\title{
Images in Practice: Replacement of an 18-Year-Old Spinal Cord Stimulator Paddle Lead with Cylindrical Leads Under Direct Visualization
}

\author{
Philip M. Shumsky - Christopher S. Wie - John A. Freeman • \\ Omar Viswanath · Naresh P. Patel
}

Received: May 27, 2020 / Published online: July 4, 2020

(C) The Author(s) 2020

Keywords: Cylindrical lead; Neuromodulation; Neurosurgery; Spinal cord stimulation (SCS); Paddle lead; Pain; Medicine

\section{CASE}

Traditionally, spinal cord neuromodulation included paddle lead placement; however, recent technological innovations have led to less invasive techniques $[1,2]$. There is debate on how to proceed with treatment in patients with previous paddle lead spinal cord stimulation (SCS) who are no longer reporting adequate pain relief, thought to be due to extensive scar tissue that can form over the paddle $[3,4]$.

Digital Features To view digital features for this article go to https://doi.org/10.6084/m9.figshare.12472628.

P. M. Shumsky $(\bowtie) \cdot$ C. S. Wie · J. A. Freeman Department of Anesthesiology and Perioperative Medicine, Mayo Clinic Hospital, Phoenix, AZ, USA e-mail: shumsky.philip@mayo.edu

\section{N. P. Patel}

Department of Neurologic Surgery, Mayo Clinic Hospital, Phoenix, AZ, USA

O. Viswanath

Valley Anesthesiology and Pain Consultants-

Envision Physician Services, Phoenix, AZ, USA

O. Viswanath

Department of Anesthesiology, Creighton

University School of Medicine, Omaha, NE, USA

\section{Key Summary Points}

\section{Background}

The origins of spinal cord neuromodulation for pain were centered around paddle lead placement requiring extensive surgery and, more often than not, permanent lead placement even after treatment sensitization. Recently, percutaneous cylindrical lead placement has fallen in favor because of the less invasive implantation, flexibility of lead placement, and improved innovative technology

\section{Aims}

The aim of this case is to demonstrate the technique used to remove a previous paddle lead implant and replace it with percutaneous cylindrical leads under direct visualization

\section{Key Findings}

A technical example of successful longterm paddle lead removal with replacement by percutaneous cylindrical leads resulting in improved pain control and decreased opioid use 
Typically, if a paddle lead is no longer effective, a revision surgery is performed to place a new paddle, which may increase the risks of abandonment technology and perioperative complications, increased treatment costs, and potential worsening of the patient's overall pain level [4-6]. This case describes a 58-year-old woman with a history multiple lower back surgeries who was originally implanted with an 8-electrode $(4 \times 2)$ paddle lead via a T11 laminectomy spanning the T10-T11 vertebrae. Years later, the patient presented with worsened pain and loss of therapy, with subsequent decision to remove the original paddle lead and place cylindrical leads compatible with her current generator system.

Fluoroscopy was utilized to identify the paddle lead, which was removed intact without complication with careful posterior surgical dissection. Two separate 8-contact cylindrical leads were then placed under direct visualization without needle guidance via the T10-T11 incision site into the epidural space. The original incision was extended cephalad along with further dissection, hemilaminotomies were

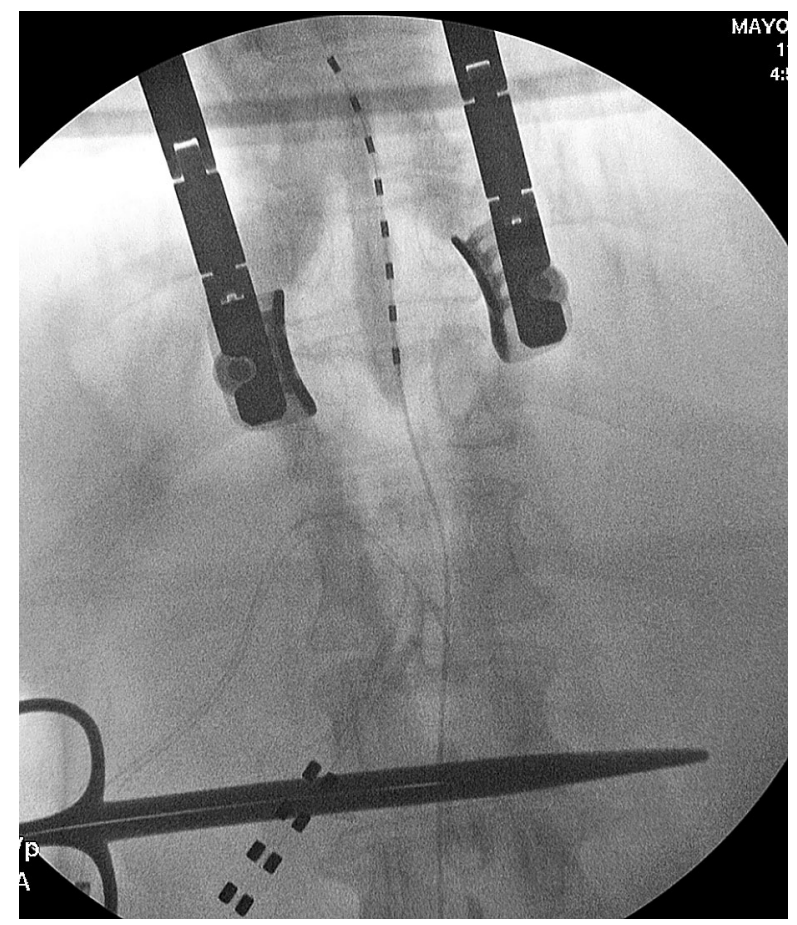

Fig. 1 Successful removal of paddle lead with insertion of first cylindrical lead

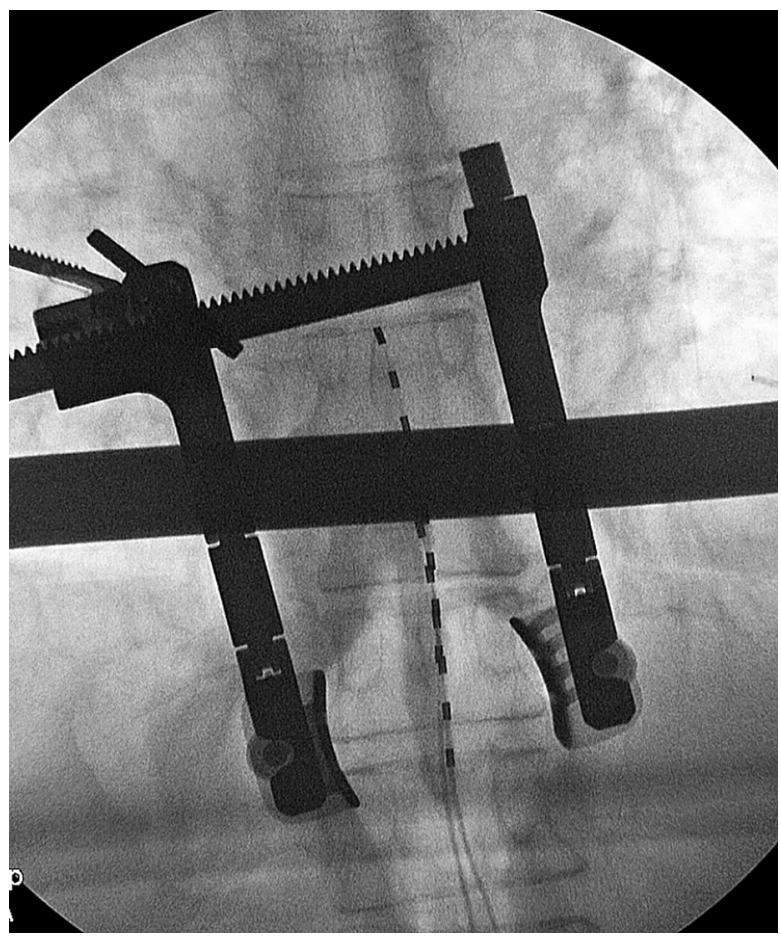

Fig. 2 Two cylindrical leads inserted through surgical site

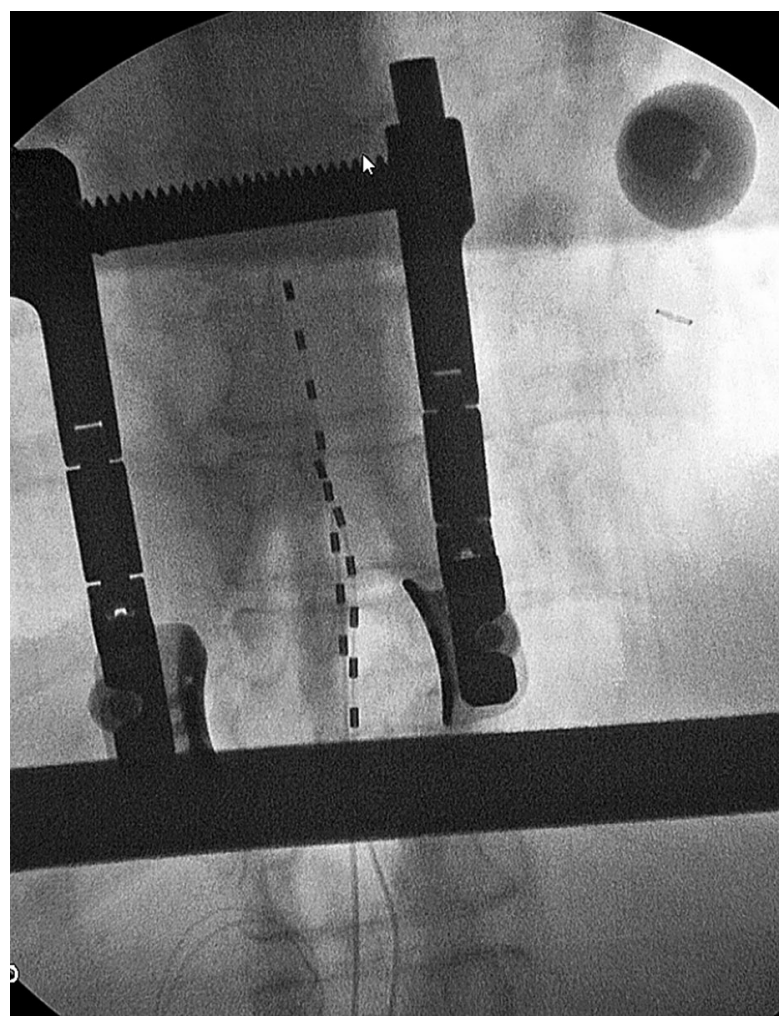

Fig. 3 Notable bowing of second cylindrical lead secondary to extensive epidural scar tissue 


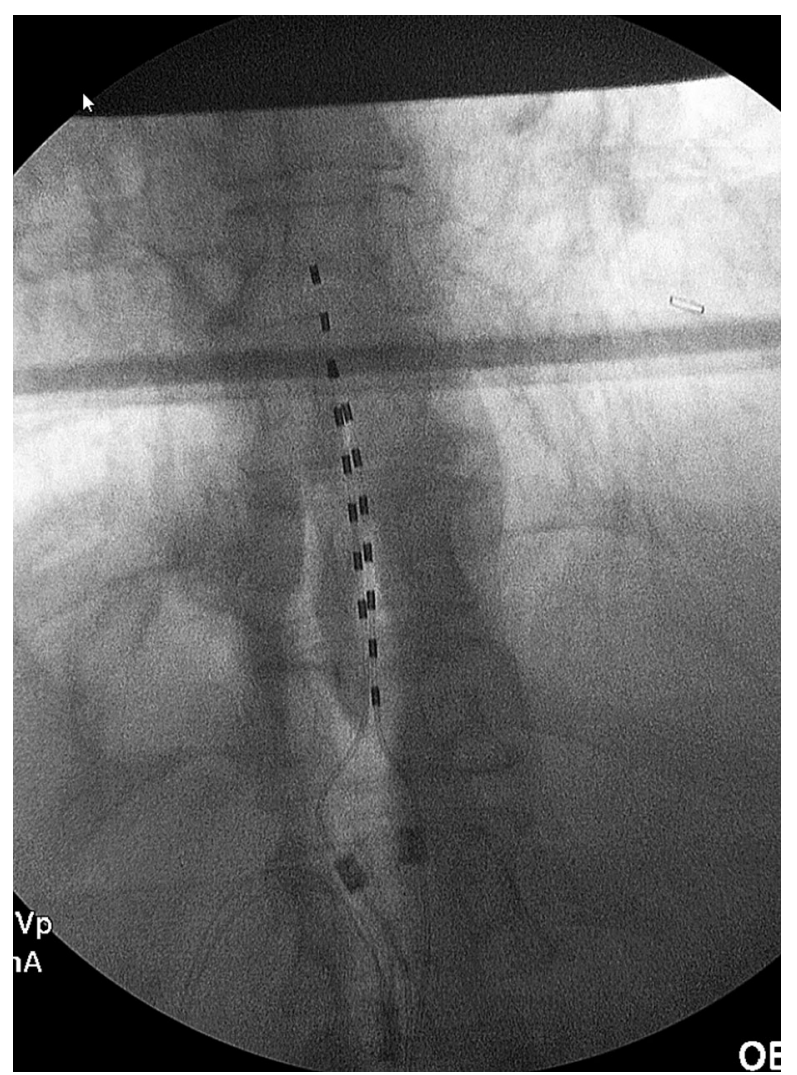

Fig. 4 Final lead position with lead anchors in place

performed to the right of the T9 and T10 vertebrae, and extensive epidural scar tissue was resected; two leads were then driven to the middle and top of the T8 and T9 vertebrae with double coverage of the T9-T10 disk space for targeted therapy. The leads were then anchored to the T12 spinous process and tunneled to the

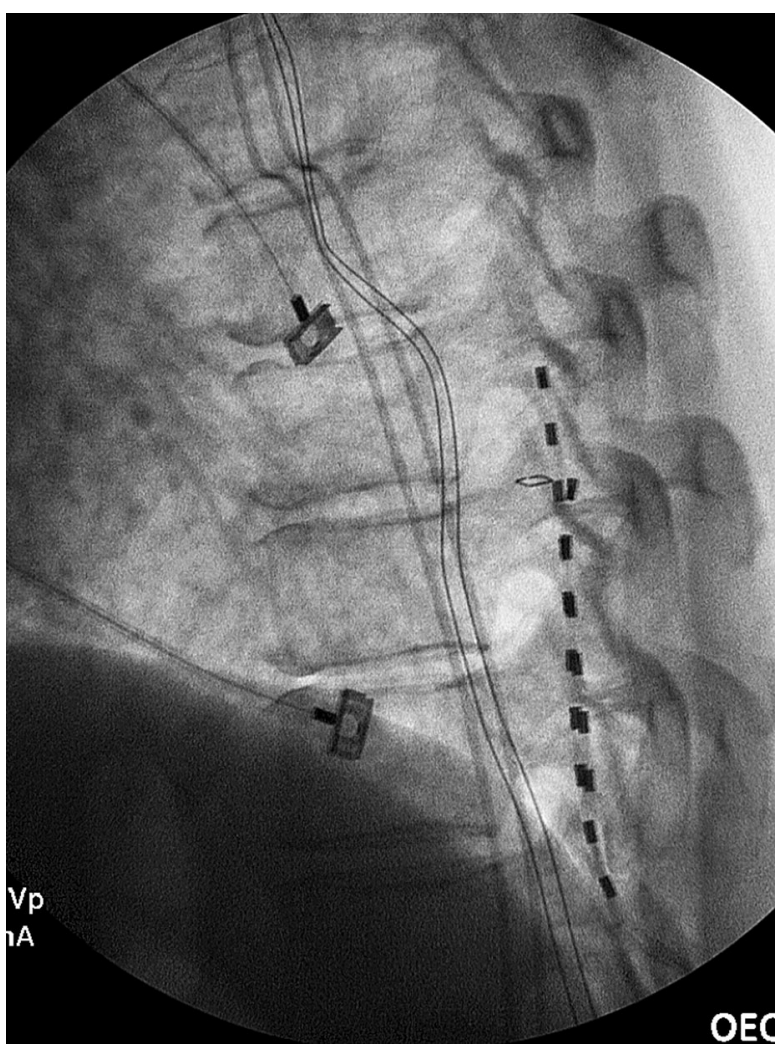

Fig. 5 Final posterior placement of cylindrical leads

implantable pulse generator (IPG) site (Figs. 1, $2,3,4,5,6,7)$. The IPG was replaced with the latest technology and implanted into the original pocket. Six weeks later, the patient reported excellent relief of her back pain and had successfully weaned off all opioid therapy. 


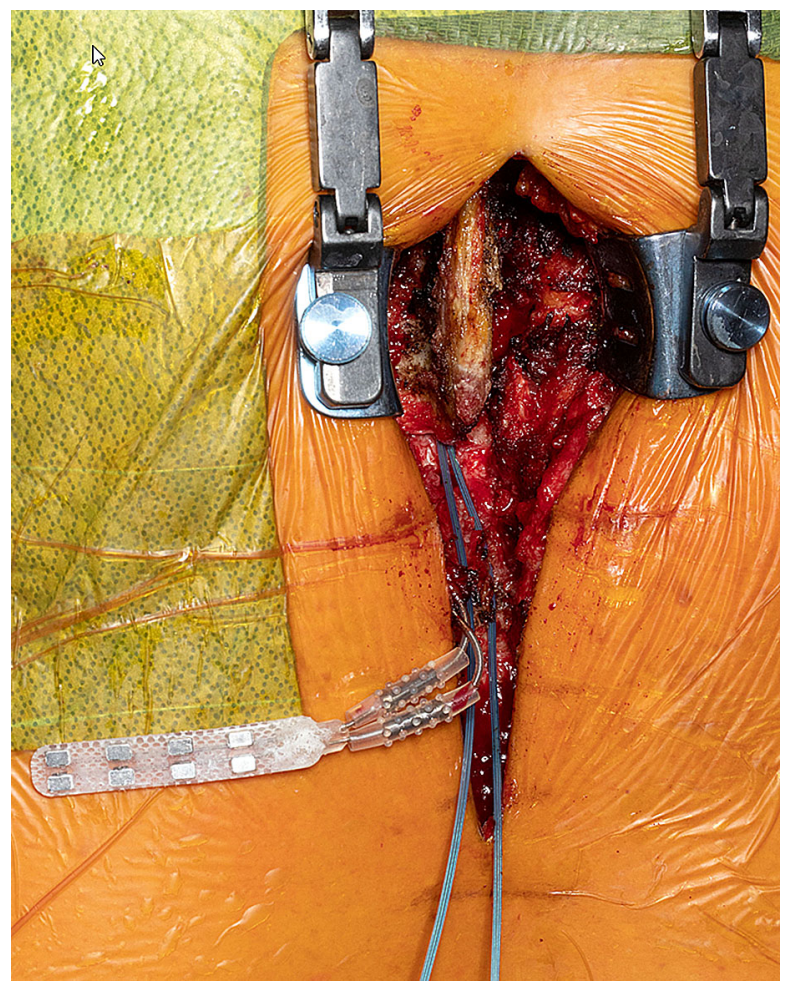

Fig. 6 Removal of paddle lead with placement of cylindrical leads under direct visualization into the epidural space

\section{ACKNOWLEDGEMENTS}

We thank you the participants of the study and the clinicians delivering comprehensive care.

Funding. No funding or sponsorship was received for this study or publication of this article.

Authorship. All named authors meet the International Committee of Medical Journal Editors (ICMJE) criteria for authorship for this article, take responsibility for the integrity of the work as a whole, and have given their approval for this version to be published.

Disclosures. Philip M. Shumsky, Christopher S. Wie, John A. Freeman, and Naresh P. Patel have nothing disclose. Omar Viswanath is a member of the journal's Editorial Board.

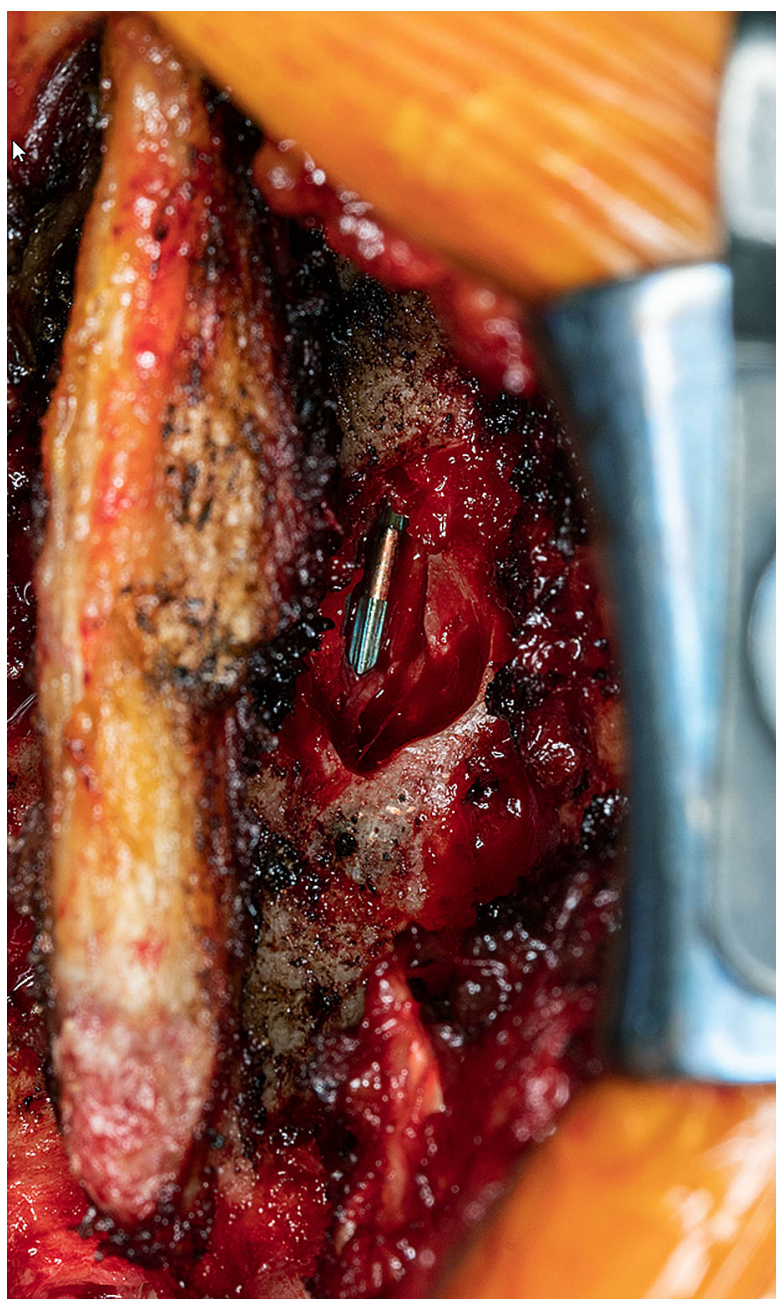

Fig. 7 Magnified image of leads passing through epidural space after hemilaminotomy was performed under direct visualization

\section{Compliance with Ethics Guidelines.}

Informed consent was obtained from the patient. No IRB approval was required given the current policies of the institution where this procedure was performed.

Peer Review. Please note, contrary to the journal's standard single-blind peer review process, this article underwent review by a member of the journal's Editorial Board.

Open Access. This article is licensed under a Creative Commons Attribution-NonCommercial 4.0 International License, which permits any non-commercial use, sharing, 
adaptation, distribution and reproduction in any medium or format, as long as you give appropriate credit to the original author(s) and the source, provide a link to the Creative Commons licence, and indicate if changes were made. The images or other third party material in this article are included in the article's Creative Commons licence, unless indicated otherwise in a credit line to the material. If material is not included in the article's Creative Commons licence and your intended use is not permitted by statutory regulation or exceeds the permitted use, you will need to obtain permission directly from the copyright holder. To view a copy of this licence, visit http:// creativecommons.org/licenses/by-nc/4.0/.

\section{REFERENCES}

1. Hegarty D. Spinal cord stimulation: the clinical application of new technology. Anesthesiol Res Pract. 2012;2012:375691.
2. Alo KM, Redko V, Charnov J. Four year follow-up of dual electrode spinal cord stimulation for chronic pain. Neuromodulation. 2002;5(2):79-88.

3. Maldonado-Naranjo AL, Frizon LA, Sabharwal NC, et al. Rate of complications following spinal cord stimulation paddle electrode removal. Neuromodulation. 2018;21(5):513-9. https://doi.org/10.1111/ner. 12643.

4. Dupré DA, Tomycz N, Whiting D, Oh M. Spinal cord stimulator explantation: motives for removal of surgically placed paddle systems. Pain Pract. 2018;18(4): 500-4. https://doi.org/10.1111/papr.12639.

5. Han JL, Murphy KR, Hussaini SMQ, et al. Explantation rates and healthcare resource utilization in spinal cord stimulation. Neuromodulation. 2017;20(4): 331-9. https://doi.org/10.1111/ner.12567.

6. Matias CM, Amit A, Lempka SF, et al. Long-term outcomes after replacement of percutaneous leads with paddle leads in a retrospective cohort of patients with spinal cord stimulation systems. Neurosurgery. 2014;75(4):430-6. https://doi.org/10.1227/NEU. 0000000000000460 (discussion 436). 